\title{
Research
}

\section{Development and Use of a Bioeconomic Model for Management of Mussel Fisheries under Different Nutrient Regimes in the Temperate Estuary of the Limfjord, Denmark}

\author{
Karen Timmermann $^{1}$, Grete E. Dinesen $^{2}$, Stiig Markager ${ }^{1}$, Lars Ravn-Jonsen $^{3}$, Marc Bassompierre $^{4}$, Eva Roth $^{3}$ and Josianne G. $^{2}$ \\ Stottrup $^{2}$
}

\begin{abstract}
Coastal ecosystems worldwide are under pressure from human-induced nutrient inputs, fishing activities, mariculture, construction work, and climate change. Integrated management instruments handling one or more of these problems in combination with socioeconomic issues are therefore necessary to secure a sustainable use of resources. In the Limfjord, a temperate eutrophic estuary in Denmark, nutrient load reductions are necessary to fulfill EU regulations such as the Water Framework Directive (WFD). The expected outcome of these load reductions is an improved water quality, but also reduced production of the abundant stock of filter-feeding blue mussels, Mytilus edulis. This is expected to have significant economic consequences for the million-euro mussel fishing industry taking place in the Limfjord today. We developed a bioeconomic model that can be used to explore the consequences of load reductions for mussel fishery as practiced today, as well as potential management options, to obtain an economically and ecologically sustainable mussel fishery. Model simulations clearly demonstrate a substantial decrease in mussel production after the nutrient load reductions necessary to obtain the targets in the WFD. With today's practice, the mussel fishery in the Limfjord will not be profitable in a future, less eutrophic estuary. However, model simulations also revealed that mussel fishery can be profitable after implementation of the WFD with a reduction in the total fishing quota, fewer fishing vessels, and a higher fishing quota per vessel.
\end{abstract}

Key Words: decision support system; ecological-socioeconomic model; eutrophication; mussel production; nutrient loading; predictive models; system-based management; Water Framework Directive

\section{INTRODUCTION}

Coastal regions are the most densely populated parts of the Earth, and human activities put the integrity of coastal marine ecosystems under pressure in various ways, e.g., from nutrient loadings, intense fishing, construction work, and climate change. Management of the many interacting pressures calls for scientifically based methods that can help to achieve sustainable use of resources while conserving nature (Nobre 2011). The management systems already in place often control these pressures on a sectorial level, even though attempts have been made to encompass multiple ecosystem components, such as guidelines for the implementation of the ecosystem approach to fisheries framework (Garcia and Cochrane 2005). This approach has encouraged the development of bioeconomic models to explore the ecological and economic consequences of management options for different species, such as shellfish (Imeson and Van den Bergh 2004), swordfish (Tserpes et al. 2009), and shrimp (Huang and Smith 2011). Such models form the basis for decision support systems (DSS) that assist managers by organizing data and making models and scenarios available in a user-friendly manner (Geertman and Stillwell 2009, Nobre 2011). An example of a practical implementation of this is the WadBOS system developed for the Dutch Wadden Sea to get a holistic overview of the system and to improve management (Engelen et al. 2003). With this tool, new policy solutions for two human activities, shellfish fishery and recreational boating, were explored in terms of economic and ecological consequences, and they included different stakeholders (information available at $\underline{\mathrm{htp}} \mathrm{Il}$ www.riks.nl/Resources/papers/ManualWadBOSInternational.pdf).
The systems approach framework (SAF) is a method for addressing policy issues in a holistic manner that was developed by the EU SPICOSA project for coastal systems that ran from 2007 to 2011 (Hopkins et al. 2011). A DSS is an essential part of the SAF. The SAF includes: (1) identification of key policy issues and stakeholders, (2) definition of system boundaries, and (3) development of conceptual models essential for the issues (Tett et al. 2011). The SAF suggests that management strategies be developed by teams including scientists, managers, and stakeholders. It incorporates a multidisciplinary scientific analysis based on available data on ecological, social, and economic processes (Hopkins et al. 2011). The development of bioeconomic models focusing on user friendliness facilitates communication with and among stakeholders and is a vital element in the practical application of the SAF in complex systems. The model presented here forms the core of a DSS for the Limfjord, a temperate eutrophic estuary in Northern Denmark.

The Limfjord is a good example of a complex coastal system with long-term pressures from multiple human activities that have induced major changes in the ecosystem. These are loss of water clarity and underwater vegetation (Krause-Jensen et al. 2012), widespread anoxia, a collapse in the populations of demersal fish, and a concurrent increase in the biomass of blue mussels, Mytilus edulis Linnaeus, 1758 (Christiansen et al. 2006) as a result of a high phytoplankton biomass. The changes in the higher trophic levels have induced a simultaneous change in the exploitation of the Limfjord estuary, where a previously thriving fishery of demersal finfish has been replaced by trawling for blue mussels

\footnotetext{
${ }^{1}$ Department of Bioscience, Aarhus University, Roskilde, Denmark, ${ }^{2}$ Section for Coastal Ecology, National Institute of Aquatic Science, Technical University of Denmark, Charlottenlund, Denmark, ${ }^{3}$ Department of Environmental and Business Economics, University of Southern Denmark, Esbjerg, Denmark, ${ }^{4}$ Novo Nordisk A/S, Kalundborg, Denmark
} 
(Dolmer and Frandsen 2002). Furthermore, a regime shift has been documented to occur in the early 1990s, with a shift from dominance by demersal fish species to that of pelagic fish species, small-bodied fish species, and invertebrates (Tomczak et al. 2013). In recent years, mussel biomass and harvest have decreased along with a decrease in nutrient loadings and phytoplankton production. With the implementation of the EU WFD, further reductions in nutrient loadings are required, causing concern among the mussel fishermen, who anticipate further reductions in the production of blue mussels.

Management of this complex system has been sectorial in its approach, with separate governance and legislation for agriculture and eutrophication abatement; fishing, including mussel harvest; and nature conservation. Sectorial management is not optimal when dealing with problems where stakeholders like farmers, who benefit from an activity with high environmental impact, are themselves not directly dependent on a healthy marine ecosystem. Furthermore, the often subtle interactions between, e.g., regulations in agriculture on one side and fishing on the other call for the development of bioeconomic models that incorporate interactions among sectors and provide a more holistic representation and understanding of these complex systems.

The aim of this study was to develop a bioeconomic model that provides an integrated description of the system, to explore management options for an ecologically and economically sustainable mussel fishery in the Limfjord. Scenarios included conditions with the present nutrient loadings and those estimated as necessary for reaching good ecological status, as stipulated in the EU WFD (http://ec.europa.eu/environment/water/waterframework/info/intro en.htm). The hypotheses tested were: (1) nutrient load reductions after implementation of the WFD would result in a decline in mussel production and a less profitable mussel fishery, and (2) changes in the management of the mussel fishery would allow a profitable mussel fishery even after implementation of the WFD. To capture the complexity of the system and at the same time have a transparent model that can be understood and accepted by stakeholders, and to keep the computational time short, we demonstrate that a combination of mechanistic process descriptions and empirical relationships in models is an effective approach.

\section{MATERIALS AND METHODS}

\section{Study site}

The Limfjord is a shallow, eutrophic fjord system with a mosaic of estuaries and sounds situated in northern Denmark, connecting westward to the North Sea and eastward to Kattegat (Fig. 1). The estuarine surface area is approximately $1526 \mathrm{~km}^{2}$ with a catchment area of $7528 \mathrm{~km}^{2}$, dominated $(62 \%)$ by agriculture (Markager et al. 2006). Over the past hundred years, total nitrogen $(\mathrm{N})$ and phosphorus $(\mathrm{P})$ loadings have increased sixfold. The highest annual loadings were of 13 tons $\mathrm{N} / \mathrm{km}^{2}$ of estuary surface area and 0.91 tons $\mathrm{P} / \mathrm{km}^{2}$ during the mid-1980s (Christiansen et al. 2006). Since then, nutrient loadings have decreased to 8.2 tons $\mathrm{N} / \mathrm{km}^{2}$ and 0.30 tons $\mathrm{P} / \mathrm{km}^{2}$ (Krause-Jensen et al. 2012). The fjord system supports a high biomass of benthic suspension feeders (Maar et al. 2010), and the mussel harvest is primarily based on dredging of natural populations of blue mussels, Mytilus edulis; only a minor contribution comes from mussel farming on lines.
Fig. 1. Map of the Limfjord area. The location of Skive Fjord is marked with an A.

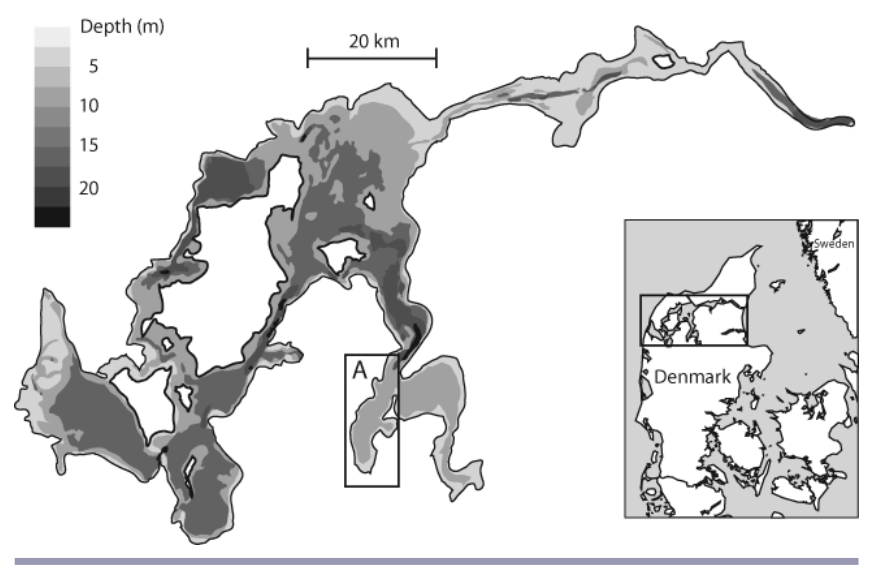

The regulation of the blue mussel fishery in the Limfjord has since 1995 been by exclusive entry license, with clear specifications on size and engine power of the vessels and quotas, as well as periods of closure (Frost 2009). The nature of the fishery, a single sedentary species and single fleet, together with the exclusive entry license, fulfill the requirements for collective action (Ostrom 1991). The strict specifications for the vessels have created a homogeneous structure which, although not a precondition, certainly eases the formation of a collective management action for the fishery. Originally, the 51 entry licenses were personal and were tied to the vessel. However, in 2009, the licenses were made tradable, which resulted in a reduction in the fleet to 38 vessels, with some having more than one license per vessel. Weekly quotas, minimum mussel size, and meat content of fishable mussels, as well as food safety regulations are under the jurisdiction of the Fisheries Directorate (BEK no. 155 of 3 July 2000, BEK no. 372 of 15 May 2009, https://www.retsinformation.dk/Forms/R0710. aspx?id=124647). However, the fishermen have voluntarily and collectively reduced their weekly quota to 45 tons per week per vessel, which is equivalent to about $50 \%$ of the official quota set by the Fisheries Directorate.

\section{Bioeconomic model}

The bioeconomic model is a fully coupled model consisting of four components (Fig. 2). These are: (1) an empirical submodel describing the relationship between nutrient loadings and phytoplankton primary production; (2) a process-based ecological submodel describing the dynamics of phytoplankton and blue mussel biomass; (3) an agent-based mussel fishing submodel that allows the fishermen to make decisions regarding fishing effort based on regulations, available mussel biomass, and expected cost and revenue; and (4) an economic submodel for cost-benefit analysis and for simulating the expected profit.

The ecological model component was based on monitoring data from the Skive Fjord sub-basin; economic data for mussel production covered the entire Limfjord (see Fig. 1) and were obtained from the Danish National Account Statistics. The ecological submodel consists of six state variables, one for phytoplankton biomass and five depicting blue mussel biomass groups (Fig. 2). The phytoplankton biomass was calculated both 
Fig. 2. Conceptual diagram of the bioeconomic model. Gray boxes represent state variables; circles and arrows represent processes.

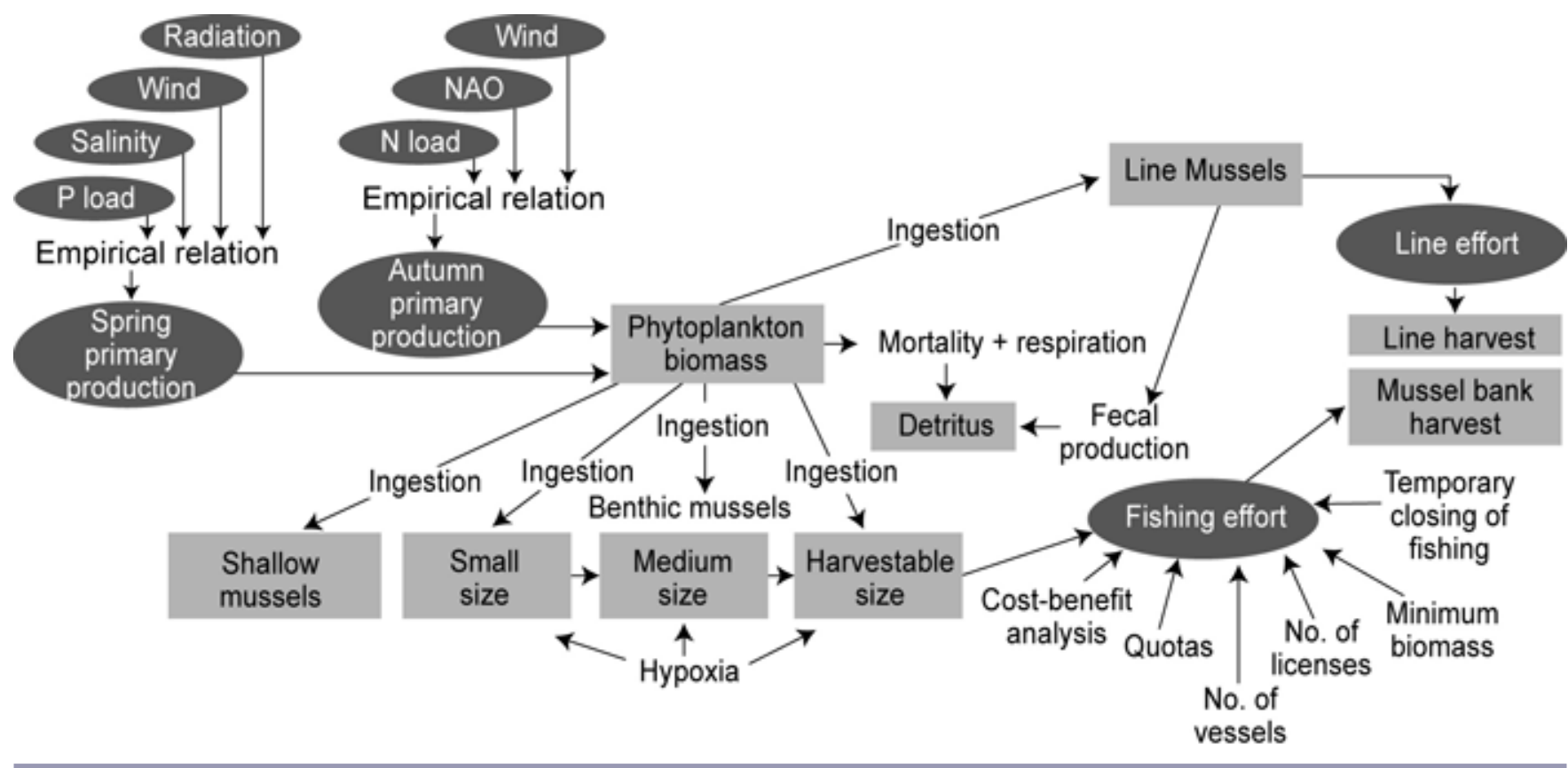

in carbon units for mussel consumption and as chlorophyll $a(\mathrm{Chl}$ a) concentration, for comparison with monitoring data. The mussel biomass groups were: M1, shallow-water mussels (depth $<2 \mathrm{~m}$ ); M2, mussels grown on long lines (aquaculture); and three size classes of mussels in deeper water (> $2 \mathrm{~m})$ : M3, small individuals of $<20 \mathrm{~mm}$ shell length (SL); M4, medium-sized individuals of 20-45 mm SL; and M5, harvestable mussels, larger than $45 \mathrm{~mm}$ SL.

Empirical models (Hinsby et al. 2012) were used to establish a simplified relationship between $\mathrm{N}$ and $\mathrm{P}$ loadings and phytoplankton primary production for two separate periods, January through June and July through December. This semiannual division was based on previous results that showed that phosphorus was the primary limiting nutrient in the spring, but nitrogen was limiting later in the growth season (Markager et al. 2006). The empirical models were established using a forwardselection multiple linear regression (MLR) method (Sokal and Rohlf 2000) on data from the Danish monitoring program in the years 1984-2003 (Markager et al. 2008) and included primary production and a selection among eight independent variables: $\mathrm{N}$ loadings, $\mathrm{P}$ loadings, freshwater runoff, seawater temperature, global surface radiation, the NAO index, salinity, and wind speed $^{3}$, where $\mathrm{N}$ and $\mathrm{P}$ loadings were added to the MLR model as forced variables. The NAO (North Atlantic Oscillation) index describes the pressure difference between Iceland and the Azores, which determines the dominant wind pattern and thereby largescale climate variations.

In the bioeconomic model, the phytoplankton biomass $(P B)$ was described as

$$
\frac{d P B}{d t}=P_{a}-k_{p} \cdot P B-\sum_{i=1}^{5} I_{i}
$$

where $P_{a}$ is the phytoplankton production rate in $\mathrm{mmol} \mathrm{C} / \mathrm{m}^{2}$ I day, determined by the empirical models; $k_{p}$ is the natural biomass-specific phytoplankton mortality rate per day, and $I_{i}$ is the ingestion of phytoplankton by mussels in group $i$ in $\mathrm{mmol} \mathrm{Cl}$ $\mathrm{m}^{2} /$ day.

Ingestion of phytoplankton by the $i$ th group of mussels depends on temperature and phytoplankton concentration, and is described as

$$
I_{i}=f(t) \cdot l_{\max _{-} i} \cdot\left(\frac{D_{i} \cdot P B}{D_{i} \cdot P B+K_{1 / 2}}\right) \cdot M_{i}
$$

where $f(T)$ is a temperature function described by an Arrhenius equation with $\mathrm{Q}_{10}=2$ (Blackford 1997), $l_{\text {max_i }}$ is the maximum biomass-specific ingestion rate $\mathrm{mmol} \mathrm{C}_{\text {phy }} / \mathrm{mmol} \mathrm{C}_{\text {mussel }} /$ day, and $D_{i}$ is a depletion factor (dimensionless) accounting for the reduction in phytoplankton concentration in the mussel bed at the bottom compared to the mean concentration in the water column). $K_{1 / 2}$ is the half saturation constant for ingestion in mmol phytoplankton $\mathrm{C} / \mathrm{m}^{3}$ and $M_{i}$ is the biomass of mussels in group $i$ in $\mathrm{mmol} \mathrm{C} / \mathrm{m}^{2}$.

The mussel biomass in the $i$ th group depends on recruitment, growth rate, and mortality rate. The growth rate is determined by the ingested amount of food, egestion, and respiration. The mortality rate includes mortality caused by natural predation, hypoxia, and catch, and hence depends on the depth and size of the mussels. Mussels in deeper waters are regularly affected by 
hypoxia, whereas mussels in shallow waters rarely experience periods of oxygen deficiency. Shore crabs (Carcinus maenas, L) and starfish (Asterias rubens), are the main mussel predators in the Limfjord, and predation pressure is therefore included for mussels in both shallow and deeper waters. In the Limfjord, dredging in shallow waters is not allowed and only mussels $>45$ $\mathrm{mm} \mathrm{SL}$ are allowed to be caught in deeper waters. Thus, only mussels in the largest size class (harvestable mussels) are affected by dredging mortality in the model. The biomass of the $i$ th mussel group is then:

\section{$S E=S E(R U D, A E P, A A D)$}

where $R e c_{i}$ is the recruitment of mussels ( $R e c_{i}$ is only $>0$ for mussels in shallow water and for the small size class in deeper water), transf $f_{i,(i+1)}$ is the transfer rate between mussel size classes, $e g$ is the fraction of the ingested food that is egested and defecated, $r$ is respiration rate, pred is predation pressure by natural predators, and hypoxia accounts for the mortality resulting from prolonged periods of oxygen deficiency. Only mussels living deeper than $2 \mathrm{~m}$ (i.e., groups M3, M4, and M5) are assumed to be affected by hypoxia. The largest size class of mussels, M5, is also subjected to loss due to dredging, i.e., catch $_{i}>0$ for large mussels. The mussel dredging submodel was designed as an adaptive agent model, so fishermen can decide on a fishing effort based on quotas, the closing of a fishery, e.g., because of the occurrence of toxic algae, harvestable mussel biomass, expected price of the harvested mussels, and variable costs. We assume that the fishermen only go fishing when the expected income from the catch is higher than the variable costs. Furthermore, the following regulations have to be followed: the fishery has to be open, not closed because of, e.g., risk of toxic algae or common agreement among the fishermen, and there should be a minimum biomass of mussels ( $\mathrm{minBio}$ ) on the fishing ground. The latter is established through a trial catch where $4 \mathrm{~kg}$ or more of harvestable size have to be present per $\mathrm{m}^{2}$.

If an area is open to fishery and the mussel harvest is profitable, the expected effort $(E)$ is determined as the least of either the effort used to catch the quota or the maximum effort.

\section{$E=$}

$$
\begin{cases}0, & \text { if } M 5<\min B i o \\ 0, & \text { if } \text { fishery is closed } \\ \min \left(\frac{q u o t a}{5 \cdot q \cdot M 5}, \text { no.of vessels }\right), & \text { if } \text { and var.costs } \leq \text { revenue } \\ 0, & \text { if var.costs }>\text { revenue }\end{cases}
$$

where quota is the maximum allowed catch/week, $q$ is the catchability coefficient, M5 is the biomass of harvestable mussels, minBio is the minimum biomass of harvestable mussels on the fishing ground, and no. of vessels is the maximum number of vessels that can be used for mussel fishery. Also var. costs are the variable costs related to fishing effort (e.g., fuel, salary), and revenue is the expected income from mussel fishery.

Besides costs related to the actual fishing effort, the total fishing costs also include fixed costs $\left(c_{f}\right)$ associated with the expenses of buying and maintaining a fishing vessel. The total cost is then:

$$
\text { total cost }=E \cdot \text { costs }_{e f}+c_{f} \cdot \text { no. of vessels }
$$

and the profit is

$$
\text { profit }=E \cdot q \cdot M 5 \cdot \text { price }_{w}-\text { total cost }
$$

where price ${ }_{w}$ is the sales price in euros per ton of harvested mussels and $E \cdot q \bullet M 5=$ catch, from eq. 4 , linking the ecological and economic components of the model.

All ecological and economic parameter values used in the bioeconomic model are listed in Table 1. Ecological parameter values for mussel recruitment, ingestion, egestion, and respiration rates are determined based on literature values (Vanharen and Kooijman 1993, Blackford 1997), and the remaining parameter values (predation and mortality) are calibrated as described under the hindcast simulation described below. The parameters used in the economic submodel are statistically estimated, based on data from the Danish National Account Statistics of fishery production. In the period 2000-2006, 11 vessels were selected that complied with the size standards of the Limfjord fishery. The vessels were not present each year; in total there were 66 observations in the sample. Data were used to calculate fixed costs $\left(c_{f}\right)$, variable costs (var. costs), and landing prices $(p)$. The landings are sold to mussel industries, which produce for the world market. The landing price is therefore assumed to reflect the world market. Hence, because the Limfjord's production is a small fraction of the world supply, it was assumed not to affect prices. The equations were solved numerically using the simulation software ExtendSim v.7.1.5. Integration was performed using Euler with a daily time step, which proved to be sufficient for the numerical precision needed.

\section{Hindcast simulation}

The model was calibrated for a period of 19 years, from 1984 to 2003. During this period, several national Water Action Plans were implemented, resulting in significant reductions in nutrient loadings to all Danish estuaries, including the Limfjord (KrauseJensen et al. 2012). Forcing data (nutrient loadings, temperature, wind speed, oxygen concentrations, etc.) for the hindcast simulation were obtained from the National Database for Marine Data (MADS) program (http://www.dmu.dk/en/-water/marinemonitoring/ mads/) and from the Danish Meteorological Institute. Parameter values for phytoplankton and mussel mortality rates were calibrated by careful and systematic tuning of the values to obtain an overall match between model-simulated and observed data for phytoplankton and mussel biomasses. Scatterplots and $\mathrm{R}^{2}$ values (Fitzpatrick 2009) were used to minimize systematic deviations and optimize goodness of fit between model-simulated and observed data.

Results from the hindcast simulation were averaged over the entire period, and annual means of Chl $a$ concentration, mussel biomass in shallow (depth $\leq 2 \mathrm{~m}$, group 1) and deeper (depth $>2 \mathrm{~m}$, sum of groups 2 through 4 ) waters were compared with annual means from monitoring data of the same time period. Weekly Chl $a$ data from the last 30 years were obtained from the monitoring station in Skive Fjord for model validation. Mussel biomass in Skive Fjord was estimated from diver observations of mussel coverage along transects, combined with core samples $\left(0.25 \mathrm{~m}^{2}\right)$ taken from 25 monitoring stations at depth intervals of $0-2,2-4$, and 4-6 m during the period 1993 to 2003. 
Table 1. Parameter values used in the bioeconomic model simulations.

\begin{tabular}{|c|c|c|c|}
\hline Parameter & Symbol & Value & Units \\
\hline $\begin{array}{l}\text { natural biomass-specific phytoplankton } \\
\text { mortality rate }\end{array}$ & $k_{p}$ & 0.38 & 1/day \\
\hline $\begin{array}{l}\text { maximum ingestion rates for mussels in group } \\
i \text {, }\end{array}$ & $l_{\text {max_i }}$ & $0.2,0.1,0.05,0.04,0.1$ & $\mathrm{mmol} \mathrm{C}_{\text {phy }} / \mathrm{mmol} \mathrm{C}_{\text {mussel }} /$ day \\
\hline \multicolumn{4}{|l|}{$i=1, \ldots, 5$} \\
\hline half saturation constant for ingestion & $\mathrm{K}_{1 / 2}$ & 20 & $\mathrm{mmol} \mathrm{C} / \mathrm{m}^{3}$ \\
\hline predation of mussels in group $i, i=1, \ldots, 5$ & pred $_{i}$ & $0.08,0.01,0,0.02,0$ & 1/day \\
\hline respiration & $r$ & 0.0027 & $1 /$ day \\
\hline depletion factor (group $1, \ldots, 5$ ) & $D_{i}$ & $0.76,0.76,0.76,0.96,0.95$ & no dimension \\
\hline transfer rate from group $i$ to $i+1$ & $\operatorname{trans}_{i,(i+1)}$ & 0.003 & 1/day \\
\hline mortality caused by hypoxia & hypoxia & 0.19 & 1/day \\
\hline catchability coefficient & $q$ & 0.0049 & 1/(fishing day) \\
\hline maximum allowed catch per week & quota & 45 & tons/week/vessel \\
\hline sales price of wild mussels & price $_{w}$ & 150 & euros/ton \\
\hline variable costs & var. costs & 480 & euros/fishing day \\
\hline fixed costs & $\mathrm{c}_{\mathrm{f}}$ & 8335 & euros/vessel/day \\
\hline minimum mussel biomass & minBio & 4 & $\mathrm{~kg} / \mathrm{m}^{2}$ \\
\hline $\begin{array}{l}\text { fraction of ingested food that is egested and } \\
\text { defecated }\end{array}$ & $e g_{i}$ & 0.25 & 1/day \\
\hline recruitment of mussels & $\operatorname{Rec}_{i}$ & 460 & $\mathrm{mmol} \mathrm{C} / \mathrm{m}^{2} /$ year \\
\hline
\end{tabular}

\section{Sensitivity tests}

Sensitivity tests were conducted for key ecological and economic parameters to determine the model sensitivity to the choice of parameter values. The tests were conducted by changing the value of a selected parameter by $1 \%, 5 \%, 20 \%$, and $50 \%$, keeping all other parameters unchanged and forcing (nutrient loading), as in the hindcast simulation.

\section{Scenarios}

Implementation of the WFD is expected to result in significant reductions in nutrient loadings. In 2011, legislative measures were passed that are expected to reduce nitrogen by $15 \%$, and an additional reduction of $17 \%$ is proposed to be implemented after 2015. It has been estimated that a total reduction of approximately $47 \%$ of the mean loadings from 1984 to 2003 is necessary to reach good ecological status for the Limfjord estuary, as required by the Water Framework Directive (Markager et al. 2006). This significant reduction is likely to affect the entire ecosystem, including mussel production and the mussel dredging industry. To explore the ecological and economic consequences of future reduction in nutrient loadings, WFD scenarios were performed by applying the same forcing values as in the hindcast simulation, but with nutrient loadings of $47 \%$ relative to the loading used in the hindcast simulation (WFD target value). In addition, scenarios exploring the optimal management of mussel fishery were done by changing the weekly quota, the total number of fishing vessels, and the number of fishing licenses per vessel, keeping the same forcing and the remaining parameters as in the hindcast simulation.

\section{RESULTS}

\section{Empirical relation between primary production and nutrient loading}

The results of the multiple linear regression (MLR) model describing the spring (months 1-6) phytoplankton primary production are shown in figures $3 \mathrm{~A}$ and $3 \mathrm{~B}$. The explanatory variables included $\mathrm{P}$ loadings, salinity, wind speed ${ }^{3}$, and surface radiation as explanatory variables. The residuals of this MLR model showed no systematic deviation, and the model could describe $73 \%$ of the interannual variation (Fig. 3B). Spring phytoplankton production in Skive Fjord declined significantly from 1984-2003 (Fig. 3A), in synchrony with declining P loadings, and $\mathrm{P}$ loadings alone described $50 \%$ of the variability in $P_{a}$, the phytoplankton production rate. Salinity is a proxy for water exchange with the North Sea, and it appeared as a negative coefficient, corresponding to dilution of the phosphorus concentration in the estuary in years with high water exchange with the North Sea. The third variable selected was the average wind stress from July back to December of the previous year. This variable had a clear negative effect on $P_{a}$ the following year, presumably due to a negative relationship between wind stress and anoxia, which enhances leakage of phosphorus from the sediment. Thus, more wind in the autumn reduced the phosphorus concentration available for phytoplankton the following spring. The fourth and last variable selected was the average surface radiation from July to December the year before. Higher radiation lowered $P_{a}$ the following year, possibly because of a positive relationship between surface radiation and the amount of nutrients consumed by plants in the autumn, lowering the phosphorus available for primary production next spring. In spring, the coefficient for $\mathrm{P}$ loadings was higher than for the other explanatory variables, 0.82 compared to 0.096 for salinity, -0.52 for wind, and -0.15 for radiation, confirming the significant impact of $\mathrm{P}$ loadings during spring. The coefficients can be compared directly because all variables were scaled to a mean value of zero and a standard deviation of 1 .

Phytoplankton production in autumn (months 7-12) was more constant over time (Fig. 3C; 1991 is considered as an outlier), compared to spring primary production. The final MLR model for autumn primary production had three variables; N loadings, NAO index, and wind speed ${ }^{3}$ (Figs. 3C, 3D). The positive effect 
of $\mathrm{N}$ loadings was as expected, but was noticeably lower than the coefficient for $\mathrm{P}$ loadings in the spring and lower than the other two explanatory variables $(\mathrm{N}$-coefficient $=0.26$ compared to -0.38 for wind speed ${ }^{3}$, and -0.69 for NAO index). The negative effects of the NAO index and wind stress in the model corresponded to the negative effect of salinity for the spring period (a proxy for water exchange and thus dilution) and the negative effect of wind on anoxia. Although there was a fairly good correlation between the MLR model for autumn phytoplankton production and measured data $\left(\mathrm{R}^{2}=0.42\right)$, the model tended to underestimate small values of primary production and overestimate large values (Fig 3D).

Fig. 3. Time series of observed values (dots) and modeled values (lines, multiple linear regression) for area phytoplankton primary production in Skive Fjord for: (A) January through June and (C) July through December. The equations for the multiple linear regression models are: For January through June: $P_{a}$ (months 1-6) $=0.82$ P loadings -0.096 Salinity -0.52 Wind $^{3}-0.15$ radiation. For July through December: $P_{a}$ (months $7-12)=0.26 \mathrm{~N}$ loadings $-0.69 \mathrm{NAO}$ index $-0.38 \mathrm{Wind}^{3}$. The coefficients are relative coefficients for data normalized to zero mean and a standard deviation of 1 . Relationships between observed and modeled values for months 1 through 6 and month 7 through 12 are shown in B and D, respectively; 1991 is considered an outlier in $\mathrm{C}$. Lines represent 1:1 ratio between measured and model values.
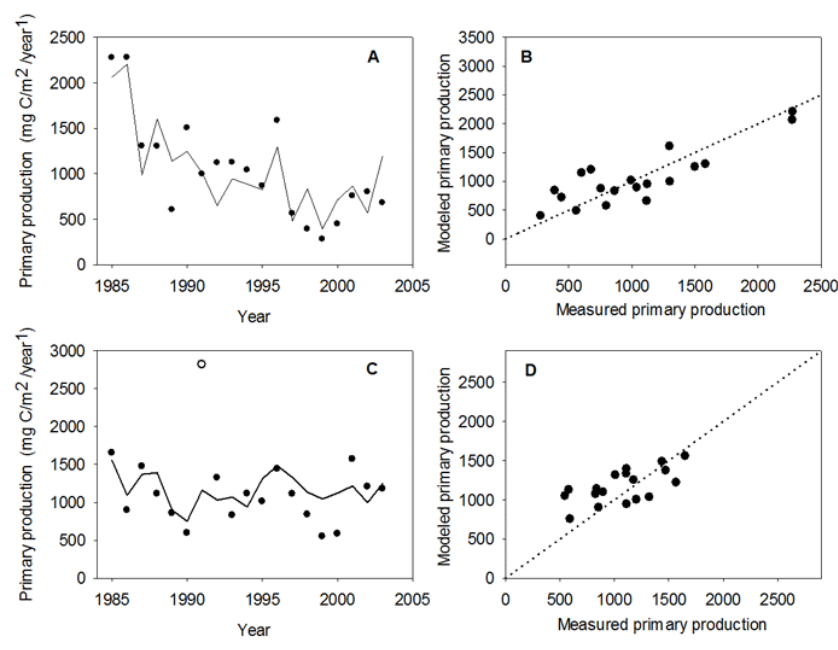

The pattern of having a strong effect of $\mathrm{P}$ loadings in the spring and a weaker effect of $\mathrm{N}$ loading in the autumn has also been observed for other Danish estuaries and for other variables than primary production (Markager et al. 2008, 2010) and probably reflects that freshwater loadings directly govern the nutrient concentrations present in the spring, whereas nutrient concentrations later in the season are more controlled by internal processes in the estuary like, e.g., the occurrence of anoxia.

\section{Hindcast simulation 1984-2003}

The annual phytoplankton dynamics in Skive Fjord, characterized by high $\mathrm{Chl} a$ concentrations during spring and summer and lower concentrations in autumn, were adequately reproduced by the model (Fig. 4A). The interannual variation, with high $\mathrm{Chl} a$ concentrations in the beginning of the simulation period (1994-1988) and lower concentrations in the remaining period, was also well described by the model. In the mid-1990s, four high Chl $a$ peaks were recorded that were not captured by the model. Good agreement was found between observed and simulated annual means of mussel biomass in shallow (depth $\leq 2$ $\mathrm{m}$ ) and deeper (depth $>2 \mathrm{~m}$ ) waters (Figs. 4B, 4C). This indicated there was a good representation of the ecosystem in this bioeconomic model. However, it was difficult to test the model's

Fig. 4. Time series plots of measured (dots) and modeled (lines): (A) Chl $a$ concentrations; (B) mussel biomass in shallow water $(\leq 2 \mathrm{~m})$, and $(\mathrm{C})$ mussel biomass in deep water $(>2 \mathrm{~m})$.
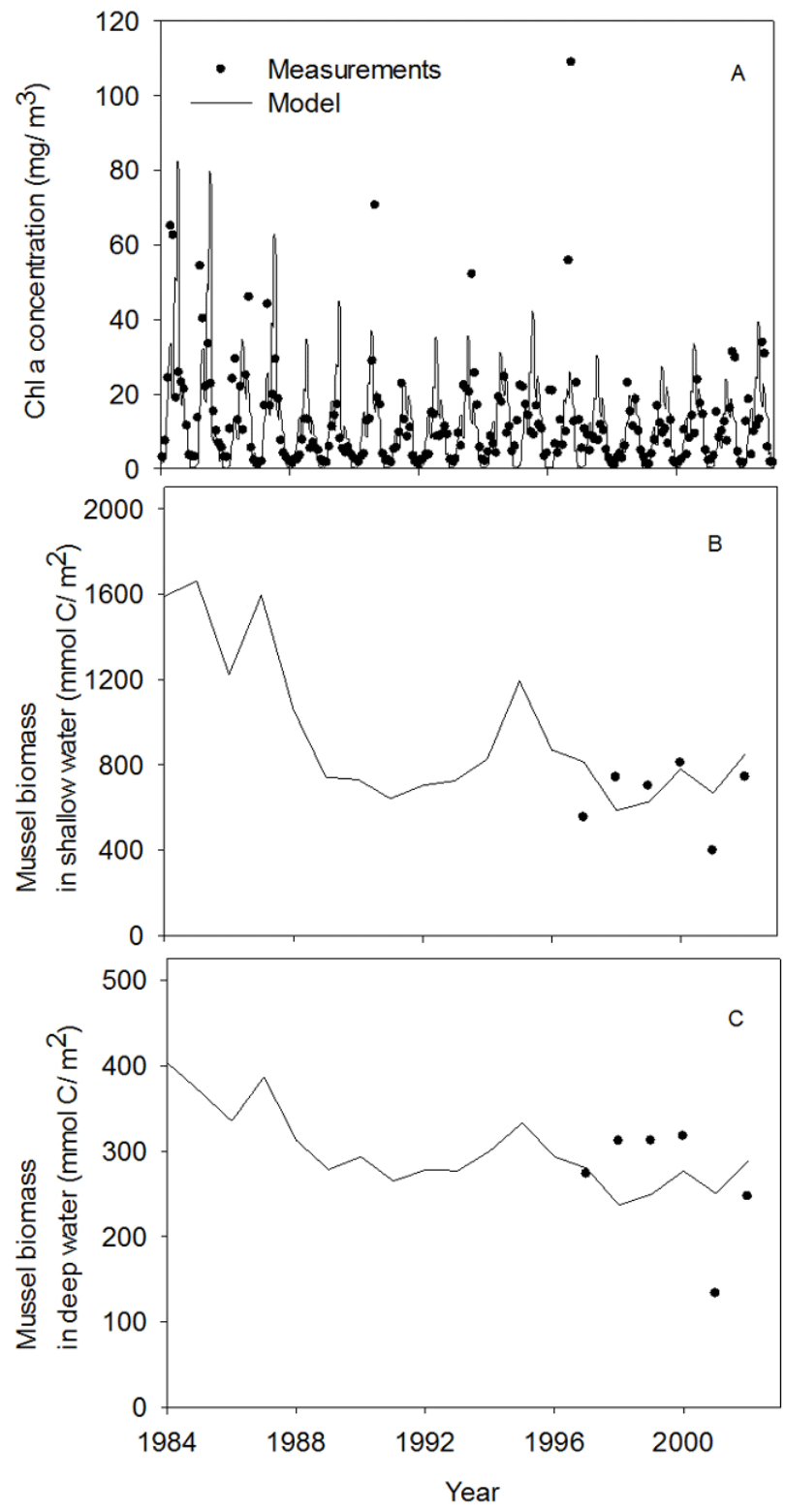
ability to describe interannual variations, because mussel biomass data from Skive Fjord were only available for the last six years of the hindcast period. Sensitivity analyses of the unconstrained parameters, such as mortality rates of phytoplankton and natural predation on mussels, revealed that the model was sensitive to larger (i.e., $\geq 20 \%$ ) changes in these parameters and that the response often propagated up through the food chain, with the lowest response for phytoplankton biomass and the highest response in profit (Fig. 5). In addition, sensitivity tests revealed strong nonlinearities. For example, a reduction in predation pressure for mussels in deep water resulted in an increased mussel biomass, whereas landings and profit were almost unaffected (Fig. 5). This indicates that predation by, e.g., starfish to a large extent controls mussel biomass, whereas landings and profit in the hindcast situation are controlled by quotas. In contrast, increased predation pressure of $50 \%$ would decrease not only mussel biomass, but also the landings and profit, by $75 \%$ and $100 \%$, respectively, indicating a competition between fishers and other mussel predators. Sensitivity analysis for the economic parameters, e.g., fixed and variable costs and sales prices, showed that the landings were unaffected by changes in the economic parameters in the tested range, but profit responded linearly to changes in parameter values.

Fig. 5. Model sensitivity to changes in predation pressure for mussels in deep water. Results are shown as percent change in response parameters relative to the hindcast simulation.

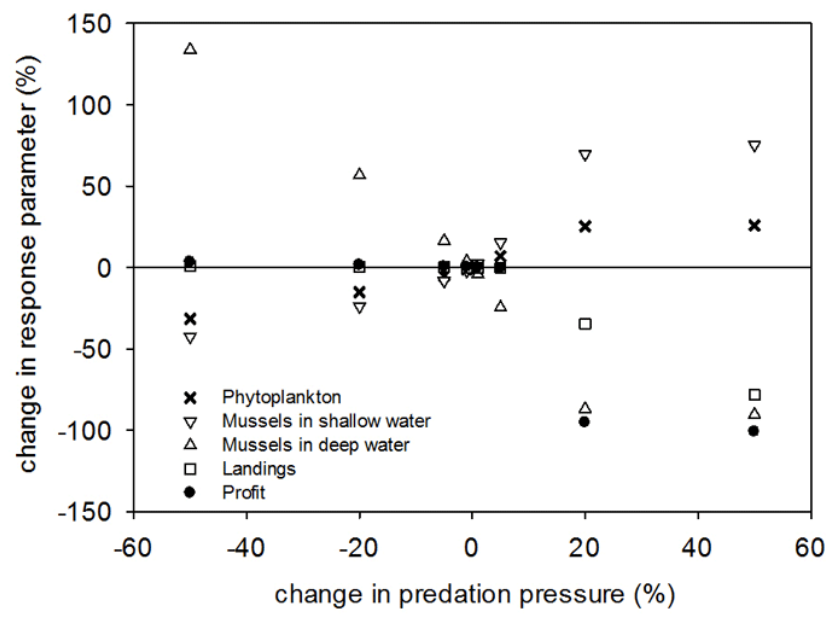

\section{Results of scenarios}

According to the model results, reduced nutrient loadings to the expected target level for WFD implementation, i.e., $47 \%$ of the average loading between 1989 and 2003, had significant effect on mussel biomass in shallow and deep water, on landings, and on profit (Figs. 6A-D). Reduction in quotas revealed that a quota of 45 tons/week/vessel would optimize landings and profit at the present level of nutrient loadings (Fig. 6D) and would ensure a high mussel biomass in deeper waters (Fig. 6B). With achievement of the WFD target level, the optimal economic quota is estimated to be $\sim 30$ tons/week/vessel. However, even with an optimal fishing quota, mussel fishery would not be profitable after implementation of WFD (Fig. 6D) because of the reduction in mussel production and biomass, especially in deeper waters (Figs. $6 \mathrm{~A}, 6 \mathrm{~B})$.

Fig. 6. Model scenarios showing the effects of fishing quotas with a constant number of vessels (A-D) and with a variable number of fishing vessels but a constant quota of 45 tons/week/ vessel (E-H) under the current nutrient load level (solid line) and after implementation of the Water Framework Directive (dashed line).
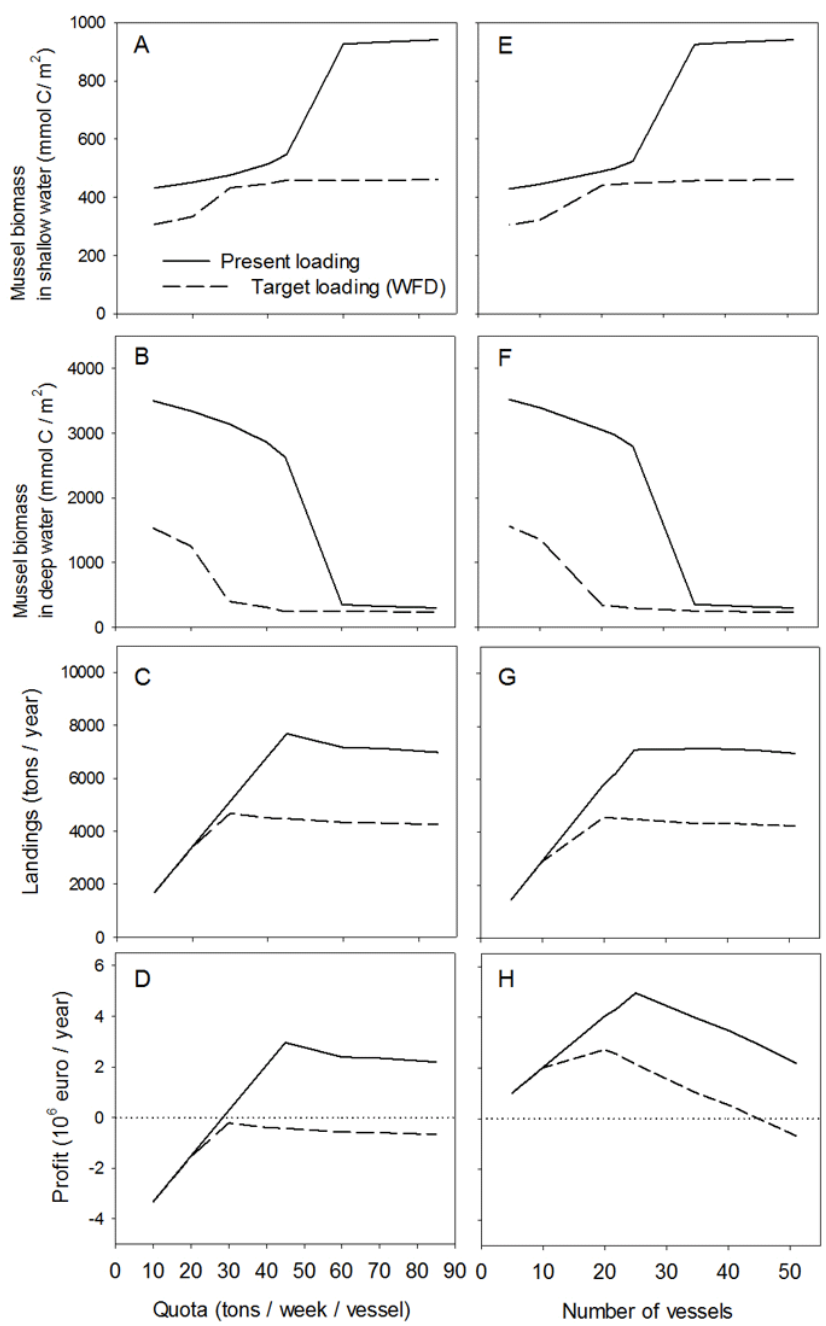

Scenarios exploring the effects of the number of mussel fishing vessels with a fixed quota of 45 tons/week/vessel (Figs. 6E-H) revealed that at the present level of nutrient loadings, the economically optimal number of vessels would be 25 . During the last few years, the number of vessels in the Limfjord has decreased from 51 to 38 , but according to the model results, the number of vessels should be reduced even further to optimize profit. Reduction in the number of vessels will reduce the exploitation level, resulting in a threefold increase in the mussel biomass at water depth $>2 \mathrm{~m}$ (Fig. 6F), whereas the increased competition for food (phytoplankton) will reduce the mussel biomass in 
shallow water by $\sim 50 \%$ (Fig. 6E). In the scenario where the loadings are reduced to a level that will fulfill the targets of the WFD, the mussels are limited by food and the productivity is therefore reduced. The reduced mussel production means that the optimal number of fishing vessels would to be 20 after implementation of the WFD (Fig. 7). If the number of vessels is higher than 20, the blue mussel population would be overexploited and would decrease to a minimum level (Fig. 6F). Maintaining 51 individual licenses after nutrient reduction to the WFD target level was shown not to be profitable, even at the optimal quota of 30 tons/week/vessel (Fig. 7). If, however, the present number of licenses is distributed among 37 vessels with a quota of a minimum of 20 tons/week/license, mussel fishery will be profitable. If even fewer vessels share the 51 licenses, mussel fishery will be profitable at even lower quotas. A quota of approximately 30 tons/week/ license optimized profit, regardless of the number of vessels.

Fig. 7. Model scenarios showing the effects of distributing 51 licenses among different numbers of vessels, and the effects of different quotas. Model scenarios are performed with a nutrient loading corresponding to the Water Framework Directive.

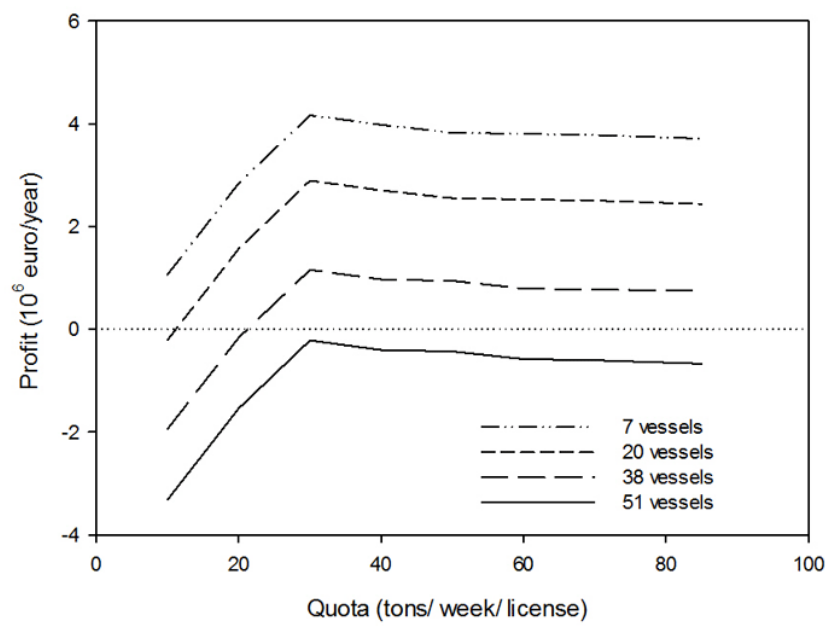

\section{DISCUSSION}

Management of the coastal zone represents a challenge and requires science-based knowledge, because of the complexity of the ecological processes and interactions with the socioeconomic system (Nobre 2011). Bioeconomic models and other crosssectorial models that encompass multiple issues are few and far between, as a result of several obstacles, such as lack of data on the appropriate scale, lack of communication across sectors and scientific disciplines, and lack of understanding of system complexity. Furthermore, multidisciplinary models become immensely complex if all subdisciplines are represented with state-of-the-art models within each discipline. Thus, working with multidisciplinary models requires flexibility and some simplification of the subparts of the model compared to present standards for each discipline. The study presented here shows the first bioeconomic model that addresses the multiple policy issues related to reaching the WFD targets for good ecological status while maintaining a profitable mussel fishery in a Danish marine coastal system. The model was developed for Skive Fjord, but is applicable for other areas where data is available. An innovative aspect was the use of empirical models to shortcut the description of the biogeochemical cycle by establishing an empirically based link between nutrient loadings and primary production (Fig. 3). Compared to a full mechanistic description of hydrodynamics and the biogeochemical cycles, the use of an empirical shortcut made the model transparent and assured a short computational time (CPU $20 \mathrm{sec} / 20$-year simulation), which is crucial for models aiming at facilitating stakeholder involvement, discussions among stakeholders and scientists, and linking data to the economy. Although the empirical submodels are not as generic as a mechanistic description, the model contains the characteristic features, such as salinity and wind (i.e., hydrodynamics), nutrient loadings, and seasonality, that control primary production. Hence, when the necessary long-term monitoring data are available, empirical linkages are useful, either alone or in combination with dynamic models, as was done in this study.

Model validation is an important tool to test model credibility and increase confidence in model scenarios (Fitzpatrick 2009). Unfortunately, validation in terms of numerical comparison of model results with empirical data is often neglected in integrated models, because of the limitation of data availability and limited human and technical resources (van Delden et al. 2007). The hindcast model run showed that the bioeconomic model was able to reproduce a 20-year time series of observed Chl $a$ data, including the decreasing trend in Chl $a$ concentration observed in the simulation period (Fig. 4A). In the mid-1980s, high $(>40 \mu$ $\left.\mathrm{g} \mathrm{L}^{-1}\right) \mathrm{Chl} a$ concentrations occurred regularly. Although the model did not capture the exact timing of these peaks, the magnitude was well reflected by the model. Decrease in Chl $a$ concentration coincided with significant reduction in P loadings, in particular. Significant relationships between nutrient loadings and Chl $a$ are not self-evident, however, because of changes in factors like internal loadings and predation by zooplankton or mussels, and the sensitivity of $\mathrm{Chl} a$ concentrations to reduction in nutrient loadings is often low (Timmermann et al. 2010). The four Chl $a$ peaks recorded in the mid-1990s were not captured by the model. These peaks, which occurred in either August or September, were most likely due to nutrient release from the anoxic sediments (Carstensen et al. 2007). This shows the limitation of the empirical model, which can reproduce the overall pattern in the interannual variation but fails to capture specific events. A dynamic model, including benthic nutrient cycling, would probably be better at capturing specific events, but it would also make the model complex, slower, and less transparent, and would hamper interactive use by stakeholders. Major changes in forcing (nutrient loading) were observed in the hindcast period, and the generally good agreement between model results and empirical data (Fig. 4) indicate that the model is not only able to reproduce data, but also responded correctly to changes in forcing, which is essential for scenario reliability. In addition, the long simulation period revealed that cumulative errors and false trends did not emerge.

There was a reasonable agreement between observed and modeled mussel biomass (Figs. 4B, 4C). The model appeared to capture the correct biomass level, but the year-to-year variation in observed biomass seemed to be higher than predicted by the 
model. In addition, the relative distribution between mussel biomass in shallow and deep waters was well reflected by the model.

In Denmark, implementation of the WFD has been driven by environmental governance and has aimed at reestablishing good ecological status, whereas management of resource utilization mainly has responded to comply with environmental targets. Such fragmented management risks failure in achieving a sustainable balance between nature conservation and resource utilization under changing pressures and baselines. In the Limfjord, mussel fishery is managed through regular environmental impact assessments that consider the carrying capacity of mussel biomass, but not the economic consequences. In response to this management, mussel fishers made a communal agreement among themselves to reduce the quota set by the authorities from 85 to 45 tons/vessel/week, which they found to be economically more viable (Dinesen et al. 2011). This stakeholder consensus for sustainable mussel fishery was endorsed by the results from the bioeconomic model, which showed optimal profits at this fishing intensity. The stakeholder consensus was based on the fishermen's collective experience, obtained from exploratory fishing to gain information on mussel abundance, size, and meat content. Although the fleet size had been reduced from 51 to 38 vessels, the fishermen were not able to reach the optimal fleet size of 25 by collective agreements, in comparison to the present model. Three reasons can account for this: (1) the agreements and actions are not based on the present model, they evolved on a less informed basis; (2) the reduction in vessels is through trade and will take some time; (3) oyster licenses have been made tradable as well, and some vessels have both oyster and mussel licenses.

With changing conditions, such as reduction of nutrient loadings and reduction of mussel biomass, fishers need to respond to a further declining resource. Especially during such changes, fishers and the environment would benefit from proactive management that can predict resource availability so as to support sustainable utilization while optimizing profit and striving to meet nature conservation requirements.

In this study, the bioeconomic model was shown to be able to predict ecological and socioeconomic consequences of system changes, including environmental pressures. The predictions are reliable as long as the state of the ecosystem is within the range supported by the data for the model. The anticipated decreased nutrient loading necessitates changes in the structure of mussel fisheries management from a vessel quota system toward a license quota system that allows a vessel to have several licenses (Fig. 7). Maintaining single quotas of 51 vessels would not be economically viable, because of the predicted lower standing stock of mussel and landings. Profit optimization suggests a reduction to 20 vessels and would optimize the profit for the mussel fishermen. However, if mussel biomass would decrease to a minimum level, a further reduction to 10 vessels would be needed to support sustainable resource utilization (Fig. 6E, 6F). With the present licensing system, this would mean allowing fewer vessels to have more than two licenses, each of $\sim 30$ tons/week. In practice, this means fewer fishers involved in this industry, and the challenge would be how to allocate licenses among fewer actors. However, the model results allow the managers to be proactive about this aspect, which could facilitate a successful outcome.
Interactions between nutrient loading and benthic production are complex, and the outcome depends on the balance between food availability and hypoxia (Timmermann et al. 2012). Although the mussel industry in the Limfjord apparently benefits from eutrophication, as shown by the model simulations we presented, eutrophication and hypoxia are known to harm other fishing industries (Huang and Smith 2011), with severe economic consequences (Huang et al. 2012), and it is likely that other ecosystem services will increase in the Limfjord as a consequence of nutrient reductions. A possible scenario could be that stationary finfish such as plaice and flounder, which decreased dramatically during the 1980s and early 1990s, presumably because of the negative effects of nutrient loadings (Christiansen et al. 2006), would return to the estuary and would support a local fishing industry. Recolonization of eelgrass is another expected effect of future nutrient load reductions; this would have significant positive effects on ecosystem services in terms of nutrient immobilization, sediment stability, and carbon storage from eelgrass meadows (Duffy 2006, Fourqurean et al. 2012). These and other potential positive effects of nutrient load reductions, e.g., on recreational fishery and tourism, are not included in the present model, and the model is therefore restricted to predicting the socioeconomic consequences for the mussel fishing industry and to exploring potential management strategies for obtaining an economic, sustainable mussel fishery with changing environmental pressures. The strength of the SAF lies in the coupling of ecological and socioeconomic components, and the inclusion of stakeholder knowledge and experience and empirical data of relevance to the ecological and socioeconomic processes of the system.

The SAF approach is generic and has been tested in various coastal areas around Europe (Hopkins et al. 2012). For example, Vermaat et al. (2012) developed a spatial dynamic model that allowed farming decisions to be improved by taking into account present and future societal settings. Melaku Canu et al. (2011) and Schernewski et al. (2012) both demonstrated how SAF could be used to address sustainable bivalve farming and to reduce illegal harvesting. With the SAF, large-scale clam farming in the Venice Lagoon could be more sustainable and could achieve social and economic benefits for the local community while reducing negative environmental impacts and social conflicts (Melaku Canu et al. 2011). Similarly, small-scale mussel production in Thermaikos Gulf could be improved through stakeholder participation; their improved understanding of the integrated management tool was developed, which provided investigative scenarios (Konstantinou et al. 2012). The combination of multidisciplinary science, stakeholder involvement, and the use of model scenarios makes the SAF approach very suitable to address policy issues that require multidisciplinary and holistic analysis and management strategies. For example, in Chesapeake Bay, illegal oyster harvesting is negatively impacting the ecosystem and negating attempts to restore oyster populations and their resilience (Bashore et al. 2012). The SAF approach could be used to engage all stakeholders and demonstrate how local individuals could benefit from an integrated management tool based on explorative scenarios in a similar manner to those of Melaku Canu et al. (2011) and Konstantinou et al. (2012). The SAF approach (Hopkins et al. 2011, 2012) provides a recognizable, transparent description of the real world and allows 
a better understanding of system complexity through bioeconomic model simulations. It engages stakeholders from the outset, thereby ensuring ownership and facilitating self-policing and higher acceptance of management regulations.

\section{CONCLUSIONS}

Model simulations with the bioeconomic model revealed a substantial decrease in secondary production after implementation of WFD, which would result in a collapse of the mussel fishery in the Limfjord estuary. However, mussel fishery can become ecologically and economically sustainable in a future, less productive environment by reducing the number of fishing vessels to approximately 10 and allowing several licenses for each vessel. The use of empirical models to shortcut complex biogeochemical cycling makes the model transparent, and it has a short computational time, which is essential for models aiming to facilitate stakeholder involvement.

Responses to this article can be read online at: http://www.ecologyandsociety.org/issues/responses. $\mathrm{php} / 6041$

\section{Acknowledgments:}

This study was partly funded by the EU 6th Framework Programme of the European Union Commission (Contract No. 036992 SPICOSA); by the national regime shift project in the Limfjord, funded by the Danish Food Industry Agency (DFFE); by the national project Nutrient Loading and Environmental Quality of Danish Estuaries, also by DFFE and by the MarBioShell project, funded by the Danish Agency for Science, Technology and Innovation. We thank Morten Hjort, Aarhus University, for technical assistance during model development. Also, we thank the senior advisory researchers Erik Hoffmann, Per Dolmer, and Per S. Kristensen; DTU Aqua, Charlottenlund; and the SPICOSA Limfjord stakeholder group for information and discussion of the Limfjord mussel productions. We are grateful to Professor Tom Hopkins, University of Naples, for valuable comments on the manuscript.

\section{LITERATURE CITED}

Bashore, C. J., H. A. Lane, K. T. Paynter, M. Naylor, J. R. Harding, and D. C. Love. 2012. Analysis of marine police citations and judicial decisions for illegal harvesting of eastern oysters (Crassostrea virginica, Gmelin 1791) in the Maryland portion of the Chesapeake Bay, United States, from 1959 to 2010. Journal of Shellfish Research 31:591-598. http://dx.doi.org/10.2983/035.031.0301

Blackford, J. C. 1997. An analysis of benthic biological dynamics in a North Sea ecosystem model. Journal of Sea Research 38:213-230. http://dx.doi.org/10.1016/S1385-1101(97)00044-0

Carstensen, J., P. Henriksen, and A. S. Heiskanen. 2007. Summer algal blooms in shallow estuaries: definition, mechanisms, and link to eutrophication. Limnology and Oceanography 52:370-384. http://dx.doi.org/10.4319/1o.2007.52.1.0370

Christiansen T., T. J. Christiansen, S. S. Markager, J. K. Petersen, and L. T. Mouritsen. 2006. Limfjorden i 100 år. Klima, hydrografi, næringsstoftilførsel, bundfauna og fisk i Limfjorden fra 1897 til
2003. Report 578. Danmarks Miljøundersøgelser. Faglig rapport fra DMU. National Environmental Research Institute, Roskilde, Denmark. [online] URL: http://www2.dmu.dk/1 viden/2 Publikationer/3 fagrapporter/rapporter/FR578.pdf

Dinesen, G. E., K. Timmermann, E. Roth, S. Markager, L. RavnJonsen, M. Hjorth, M. Holmer, and J. G. Støttrup. 2011. Mussel production and water framework directive targets in the Limfjord, Denmark: an integrated assessment for use in system-based management. Ecology and Society 16(4): 26. http://dx.doi. org/10.5751/ES-04259-160426

Dolmer, P., and R. P. Frandsen. 2002. Evaluation of the Danish mussel fishery: suggestions for an ecosystem management approach. Helgoland Marine Research 56:13-20. http://dx.doi. org/10.1007/s10152-001-0095-6

Duffy, J. E. 2006. Biodiversity and the functioning of seagrass ecosystems. Marine Ecology-Progress Series 311:233-250. http:// dx.doi.org/10.3354/meps311233

Engelen, G., I. Uljee, and K. Van de Ven. 2003. WadBOS: Integrating knowledge to support policy-making for the Wadden Sea. Pages 513-537 in S. Geertman, and J. Stillwell, editors. Planning support systems in practice. Springer, Berlin, Heidelberg, Germany. http://dx.doi.org/10.1007/978-3-540-24795-1_28

Fitzpatrick, J. J. 2009. Assessing skill of estuarine and coastal eutrophication models for water quality managers. Journal of Marine Systems 76:195-211. http://dx.doi.org/10.1016/j. jmarsys.2008.05.018

Fourqurean, J. W., C. M. Duarte, H. Kennedy, N. Marba, M. Holmer, M. A. Mateo, E. T. Apostolaki, G. A. Kendrick, D. Krause-Jensen, K. McGlathery, and O. Serrano. 2012. Seagrass ecosystems as a globally significant carbon stock. Nature Geoscience 5:505-509. http://dx.doi.org/10.1038/ngeo1477.

Frost, H. S., J. L. Andersen, and M. Nielsen. 2009, Økonomisk tilpasning til miljømål i blåmuslingefiskeriet. Nationaløkonomisk tidsskrift 147(2):158-174.

Garcia, S. M., and K. L. Cochrane. 2005. Ecosystem approach to fisheries: a review of implementation guidelines. ICES Journal of Marine Science 62:311-318. http://dx.doi.org/10.1016/j. icesjms.2004.12.003

Geertman S., and J. Stillwell, editors. 2009. Planning support systems best practice and new methods. Springer. http://dx.doi. org/10.1007/978-1-4020-8952-7

Hinsby, K., S. Markager, B. Kronvang, J. Windolf, T. O. Sonnenborg, and L. Thorling. 2012. Threshold values and management options for nutrients in a catchment of a temperate estuary with poor ecological status. Hydrology and Earth System Sciences 16:2663-2683. http://dx.doi.org/10.5194/hess-16-2663-2012

Hopkins, T. S., D. Bailly, R. Elmgren, G. Glegg, A. Sandberg, and J. G. Støttrup. 2012. A systems approach framework for the transition to sustainable development: potential value based on coastal experiments. Ecology and Society 17(3): 39. http://dx.doi. org/10.5751/ES-05266-170339

Hopkins, T. S., D. Bailly, and J. G. Støttrup. 2011. A systems approach framework for coastal zones. Ecology and Society 16 (4): 25. http://dx.doi.org/10.5751/ES-04553-160425 
Huang, L., L. A. B. Nichols, J. K. Craig, and M. D. Smith. 2012. Measuring welfare losses from hypoxia: the case of North Carolina Brown Shrimp. Marine Resource Economics 27:3-23. http://dx.doi.org/10.5950/0738-1360-27.1.3

Huang, L., and M. D. Smith. 2011. Management of an annual fishery in the presence of ecological stress: the case of shrimp and hypoxia. Ecological Economics 70:688-697. http://dx.doi. org/10.1016/j.ecolecon.2010.11.003

Imeson, R. J., and J. C. J. M. Van den Bergh. 2004. A bioeconomic analysis of a shellfishery: the effects of recruitment and habitat in a metapopulation model. Environmental \& Resource Economics 27:65-86. http://dx.doi.org/10.1023/B:EARE.0000016797.30911.3f

Konstantinou, Z. I., Y. N. Krestenitis, D. Latinopoulos, K. Pagou, S. Galinou-Mitsoudi, and Y. Savvidis. 2012. Aspects of musselfarming activity in Chalastra, Thermaikos Gulf, Greece: an effort to untie a management Gordian Knot. Ecology and Society 17 (1): 1. http://dx.doi.org/10.5751/ES-04455-170101

Krause-Jensen, D., S. Markager, and T. Dalsgaard. 2012. Benthic and pelagic primary production in different nutrient regimes. Estuaries and Coasts 35:527-545. http://dx.doi.org/10.1007/ $\underline{\text { s12237-011-9443-1 }}$

Maar, M., K. Timmermann, J. K. Petersen, K. E. Gustafsson, and L. M. Storm. 2010. A model study of the regulation of blue mussels by nutrient loadings and water column stability in a shallow estuary, the Limfjorden. Journal of Sea Research 64:322-333.http://dx.doi.org/10.1016/j.seares.2010.04.007

Markager, S., M. Bassompierre, and D. L. J. Petersen. 2008. Analyse af miljotilstanden i Mariager Fjord fra 1986 til 2006. Empirisk modellering af miljotilstanden. Report 685. National Environmental Research Institute, Aarhus University, Aarhus, Denmark. [online] URL: http://www2.dmu.dk/Pub/FR685.pdf

Markager S., Carstensen J., Krause-Jensen D., Windolf J., and Timmermann K. 2010. Effekter af øgede kvalstoftilførsler påmiljø $i$ danske fjorde. Report 787, National Environmental Research Institute, Aarhus University, Aarhus, Denmark. [online] URL: http://www2.dmu.dk/Pub/FR787.pdf

Markager S., L. M. Storm, and C. A. Stedmon. 2006. Limfjordens miljøtilstand 1985 til 2003. Sammenhang mellem naringsstoftilforsler, klima og hydrografi belyst ved empiriske modeller. Report 577, National Environmental Research Institute, Roskilde, Denmark.

Melaku Canu, D., P. Campostrini, S. Dalla Riva, R. Pastres, L. Pizzo, L. Rossetto, and C. Solidoro. 2011. Addressing sustainability of clam farming in the Venice Lagoon. Ecology and Society 16(3): 26. http://dx.doi.org/10.5751/ES-04263-160326

Nobre, A. M. 2011. Scientific approaches to address challenges in coastal management. Marine Ecology-Progress Series 434:279-289. http://dx.doi.org/10.3354/meps09250

Ostrom E. 1991. Governing the commons: the evolution of institutions for collective action. Cambridge University Press, Cambridge, UK. http://dx.doi.org/10.1017/CBO9780511807763

Schernewski, G., N. Stybel, and T. Neumann. 2012. Zebra mussel farming in the Szczecin (Oder) Lagoon: water-quality objectives and cost-effectiveness. Ecology and Society 17(2): 4. http://dx.doi. org/10.5751/ES-04644-170204
Sokal, R. R., and F. J. Rohlf. 2000. Biometry: the principles and practice of statistics in biological research. Third edition. W. H. Freeman, New York, New York, USA.

Tett, P., A. Sandberg, and A. Mette, editors. 2011. Sustaining coastal zone systems. Dunedin Academic Press, Devon, UK.

Timmermann, K., S. Markager, and K. E. Gustafsson. 2010. Streams or open sea? Tracing sources and effects of nutrient loadings in a shallow estuary with a 3D hydrodynamic-ecological model. Journal of Marine Systems 82:111-121. http://dx.doi. org/10.1016/j.jmarsys.2010.04.008

Timmermann, K., J. Norkko, U. Janas, A. Norkko, B. G. Gustafsson, and E. Bonsdorff. 2012. Modelling macrofaunal biomass in relation to hypoxia and nutrient loading. Journal of Marine Systems 105:60-69. http://dx.doi.org/10.1016/j.jmarsys.2012.06.001

Tomczak, M., G. E. Dinesen, E. Hoffmann, M. Maar, and J. G. Støttrup. 2013. Integrated trend assessment of ecosystem changes in the Limfjord (Denmark): evidence of a recent regime shift? Estuarine Coastal and Shelf Science 117:178-187. http://dx.doi. org/10.1016/j.ecss.2012.11.009

Tserpes, G., E. Tzanatos, P. Peristeraki, V. Placenti, and L. Kell. 2009. A bio-economic evaluation of different management measures for the Mediterranean swordfish. Fisheries Research 96:160-166. http://dx.doi.org/10.1016/j.fishres.2008.10.008

van Delden, H., P. Luja, and G. Engelen. 2007. Integration of multi-scale dynamic spatial models of socio-economic and physical processes for river basin management. Environmental Modelling \& Software 22:223-238. http://dx.doi.org/10.1016/j. envsoft.2005.07.019

Vanharen, R. J. F., and S. A. L. M. Kooijman. 1993. Application of a dynamic energy budget model to Mytilus edulis (L). Netherlands Journal of Sea Research 31:119-133. http://dx.doi. org/10.1016/0077-7579(93)90002-A

Vermaat, J. E., S. Broekx, B. Van Eck, G. Engelen, F. Hellmann, J. L. De Kok, H. Van der Kwast, J. Maes, W. Salomons, and W. Van Deursen. 2012. Nitrogen source apportionment for the catchment, estuary, and adjacent coastal waters of the River Scheldt. Ecology and Society 17(2): 30. http://dx.doi.org/10.5751/ ES-04889-170230 